Permafrost thawing in organic Arctic soils accelerated by ground heat production

Hollesen, Jørgen; Matthiesen, Henning; Møller, Anders Bjørn; Elberling, Bo

Published in:

Nature Climate Change

DOI:

10.1038/nclimate2590

Publication date:

2015

Document version

Peer reviewed version

Citation for published version (APA):

Hollesen, J., Matthiesen, H., Møller, A. B., \& Elberling, B. (2015). Permafrost thawing in organic Arctic soils accelerated by ground heat production. Nature Climate Change, 5(6), 574-578.

https://doi.org/10.1038/nclimate2590 


\title{
Permafrost thawing in organic Arctic soils accelerated by ground heat production
}

Running title: Heat production controls the ground thermal regime

\author{
Jørgen Hollesen ${ }^{1,2}$, Henning Matthiesen ${ }^{2}$, Anders Bjørn Møller ${ }^{1}$, Bo Elberling ${ }^{1 *}$ \\ ${ }^{1}$ Center for Permafrost (CENPERM), Department of Geosciences and Natural Resource Management \\ (IGN), University of Copenhagen, Øster Voldgade 10, 1350 Copenhagen K, Denmark \\ ${ }^{2}$ Department of Conservation and Natural Sciences, The National Museum of Denmark, IC \\ Modewegsvej, Brede, 2800 Lyngby, Denmark
}

*Correspondence: be@ign.ku.dk

Number of words: Summary $=168$ words; main text $=2058$ words; methods $=787$ words

Number of figures: 4

Number of tables: 0

Resubmitted to Nature Climate Change

February, 2015 
Decomposition of organic carbon (OC) from thawing permafrost soils and the resulting release of $\mathrm{C}$ to the atmosphere are considered to represent a potentially critical global-scale feedback on climate change ${ }^{1,2}$. The accompanying heat production from microbial metabolism of organic material has been recognized as a potential positive-feedback mechanism that would enhance permafrost thawing and the release of $C^{3,4}$. This internal heat production is poorly understood, however, and the strength of this effect remains unclear ${ }^{3}$. Here, we have quantified the variability of heat production in contrasting organic permafrost soils across Greenland and tested the hypothesis that these soils produce enough heat to reach a tipping point after which internal heat production can accelerate the decomposition processes. Results show that the impact of climate changes on natural organic soils can be accelerated by microbial heat production with crucial implications for the amounts of $\mathrm{C}$ being decomposed. The same is shown to be true for organic middens $^{5}$ with the risk of losing unique evidences of early human presence in the Arctic.

Approximately $50 \%$ of the global below-ground organic carbon (OC) pool is stored in the Northern circumpolar permafrost region ${ }^{6,7}$. Permafrost thaw and subsequent microbial decomposition are expected to increase the amount of $\mathrm{C}$ being released to the atmosphere with a potential global impact ${ }^{1,8}$. The OC in organic soils is more labile and thereby more prone to decomposition than in mineral soils because of a markedly higher content of O-Alkyl-C and less Aromatic-C ${ }^{9}$. Some of the most labile carbon pools described from the Arctic are found at sites where the OC was deposited relatively quickly (months to years), buried and subsequently kept under near water saturation ever since ${ }^{10}$. These are mainly peatlands (with or without palsas) holding $15-20 \%$ of the total northern circumpolar permafrost $\mathrm{OC}^{1}$ but also sites such as archaeological middens made by humans and representing an 
archive of the earliest human presence in the $\operatorname{Arctic}^{11}$. We test the hypothesis that internal heat production can accelerate decomposition in high latitude organic soils and amplify permafrost thawing.

We investigated the heat production in 21 contrasting organic permafrost soils from 6 sites in Greenland that were all within the continuous permafrost zone (Fig.1; Supplementary Table S1). The heat production was measured calorimetrically at $16^{\circ} \mathrm{C}$ on triplicates of each sample as previously described $^{12}$. The results show a heat production between 1.3 and $12.3 \mathrm{~J} \mathrm{~g} \mathrm{dry} \mathrm{soil}^{-1}$ day $^{-1}$ with a mean of

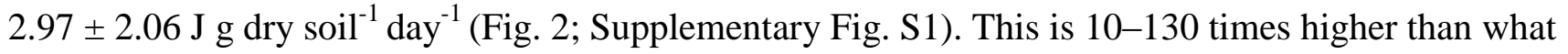
has previously been reported at a similar temperature from a mineral permafrost soils in Northeast Greenland $^{13}$. This highlights the importance of heat production from organic soils (peat) compared to non-organic sediments with an organic $\mathrm{C}$ content of typically less than $5 \%$. Except for markedly more heat-producing samples from Disko Island, the observed heat production was similar across soil types and locations and could not be related to the total carbon content in the samples $(15-45 \% \mathrm{C}$, Supplementary Table S1).

Direct measurements of heat production rates are difficult to perform at low temperatures due to the risk of condensation within the equipment. Instead, we used the oxygen consumption method ${ }^{14}$ to quantify the temperature sensitivity of decomposition at temperatures relevant for permafrost thaw by measuring the oxygen consumption at 0.5 and $16{ }^{\circ} \mathrm{C}$ on all samples (Supplementary Fig. S2a). Rates at $16{ }^{\circ} \mathrm{C}$ varied between 0.1 and $0.7 \mathrm{mg} \mathrm{O}_{2} \mathrm{~g}_{\text {dry }}$ soil $^{-1}$ day $^{-1}$ and variations between samples were significantly positive correlated with observed heat production $\left(\mathrm{r}^{2}=0.89, \mathrm{p}<0.01\right)$. Furthermore, it was possible to obtain a good estimate of the absolute heat production when assuming that one mole of 
oxygen is used to oxidize one mole of $\mathrm{C}$ releasing $40 \mathrm{MJ} \mathrm{kg} \mathrm{C}^{-1}$ as previously proposed ${ }^{3}$ (Supplementary Fig. S1).

Oxygen consumption results showed consistent $Q_{10}$ values between 1.5 and 3.6, with a mean of $2.5 \pm$ 0.5 ( \pm 1 stdev), which are in good agreement with other studies of organic permafrost soils ${ }^{15,16}$. This approach was successfully validated based on additional measurements of heat production on three of the samples at 20,25 and $30{ }^{\circ} \mathrm{C}$. No significant difference was found in the $\mathrm{Q}_{10}$ values derived from the two methods (Supplementary Fig. S2b; Supplementary Table S2).

The importance of soil water drainage on heat production was investigated (at $16{ }^{\circ} \mathrm{C}$ ) by measuring the heat production in 6 depth-specific samples from the organic-rich Qajaa kitchen midden (part of the Ilulissat Icefjord World Heritage Site) in the eastern part of the Disko Bay region in the central part of West-Greenland (Supplementary Fig. S3). In this experiment, sterilized deionized water was first added to mimic the anoxic conditions expected during initial thawing, and after the first round of measurements, the samples were freely drained and exposed to air for $24 \mathrm{~h}$ to mimic oxic conditions before repeating the measurements. Results showed a heat production in the organic cultural layers between 1.3 to $2.6 \mathrm{~J}$ g dry soil ${ }^{-1}$ day $^{-1}\left(\right.$ mean $=1.8 \mathrm{~J} \mathrm{~g} \mathrm{dry} \mathrm{soil}^{-1}$ day $^{-1}$ ), but upon drainage, the average heat generation increased by more than $200 \%$ and in some layers by as much as $350 \%$ (Supplementary Fig. S4). This marked increase in heat production is consistent with the increasing oxygen availability following drainage, faster decomposition and higher heat production rates.

We used the well-established heat and water flow model, The CoupModel ${ }^{17}$ to perform a detailed investigation of the coupling between climate change, permafrost thaw, decomposition and internal 
heat production. The model has previously been used successfully to predict permafrost thawing ${ }^{13}$. For this study, the model was first calibrated to fit measured soil temperatures and soil water contents (from 2011-2012) at the Qajaa kitchen midden (Supplementary Fig. S3). Site specific measurements of meteorological conditions, snow depths, soil thermal and physical properties were used as input to the model (See Supplementary Methods and Figs. S5-7). A detailed description of the calibration process is found in the supplementary information. After the calibration process, the model setup was successfully validated based on measured soil temperatures and soil water contents from 2010-2011 (Supplementary Figs. S8-9; Supplementary Tables S3-4). Furthermore, in order to verify that the model was representative for other sites and types of organic soils, we also included environmental data from the study site near the Zackenberg Research Station in central Northeast Greenland $\left(74^{\circ} 30^{`} \mathrm{~N}\right.$, $\left.20^{\circ} 30^{`} \mathrm{~W}\right)$. After changing only the meteorological input data and adjusting the snow density to measured values from Zackenberg (Supplementary Fig. S10; Supplementary Table S5), the ground thermal regime was successfully validated against observed soil temperatures in Zackenberg. The fact that it was possible to use the model successfully on two contrasting sites confirmed the robustness of the model setup.

The tested model setup was used to investigate the effect of future climate warming on the active layer thickness by simulating two different climate change scenarios: 1. (low) based on the minimum and 2 . (high) the maximum range of predictions from RCP4.5 (IPCC) ${ }^{18}$ and amplified according to previous modelling for Greenland ${ }^{19}$. The scenarios were applied for two of the study areas (Fig.1): the relatively warm Disko Bay area in West Greenland (mean annual air temperature, MAAT $=-4{ }^{\circ} \mathrm{C}$ ) and the relatively cold Zackenberg area in North-east Greenland (MAAT $=-9^{\circ} \mathrm{C}$ ). 
In order to investigate the interactions between permafrost thaw, decomposition of OC and heat production, a three-pool decomposition/heat production module was included in the CoupModel. Based on values used in other studies ${ }^{8,16,20-23}$, the total pool of $\mathrm{C}$ was divided into a fast (5\%), a slow (50\%) and a passive pool (45\%), and the total observed decomposition rate (heat production) was considered a sum of three pool-specific rates with turnover times (under drained conditions at $5{ }^{\circ} \mathrm{C}$ ) of 2,5 and $>4,000$ years respectively. The absolute loss of carbon was calculated for each soil layer at each time step (daily basis) and adjusted to the depth-specific temperatures and water contents according to the specific climate change scenarios. The response to temperature was described using a $\mathrm{Q}_{10}$ value of 2.5 (the average of measured values), and the response to soil moisture was described based on a previously reported sensitivity function ${ }^{24}$ that was set to fit the results from our drainage experiment with the decomposition being lower under wet and very dry conditions (Supplementary Fig. S11). The decomposition and corresponding heat production were applied in layers from the bottom of the current active layer and down to $3 \mathrm{~m}$ depth and only at soil temperatures above $0.5^{\circ} \mathrm{C}$.

The results (without considering heat production) show that a $2.2-5.2^{\circ} \mathrm{C}$ warming from $2012-2100$ is likely to increase the maximum active layer depth by $15-110 \mathrm{~cm}$ in the Disko Bay area and 5-20 $\mathrm{cm}$ in the Zackenberg area (Figs. 3A\&B). Depending on the degree of warming given by the minimum/maximum range of predictions from RCP4.5, $1-4 \%$ of the total pool of OC (depth integrated from 0.5-3.0 m depth) could be lost from the thawing permafrost layers in the Disko Bay area and 0.2$1.5 \%$ in the Zackenberg area (depth integrated from $0.3-3.0 \mathrm{~m}$ depth). 
When including heat production in the simulations, results show that observed heat production is high enough to trigger a feedback loop between soil temperatures and decomposition - but only under sufficiently warm conditions. For the cold Zackenberg area, the effect of heat production is limited, even if temperatures increase by $5.2^{\circ} \mathrm{C}$, whereas for the warmer Disko Bay, heat production could have a major effect (Fig. 3C; Supplementary Figs. S12-13). Simulations show that a $5.2{ }^{\circ} \mathrm{C}$ warming with internal heat production included (mean \pm one standard deviation) could increase the mean annual ground temperatures (from $2090-2099)$ with an additional $1.8-6.7^{\circ} \mathrm{C}\left(\right.$ mean $\left.=3{ }^{\circ} \mathrm{C}\right)$. This warming leads to thawing of the entire organic permafrost layer from 0.5-3.0 m depth (Fig. 3C) and a Carbon loss of $15-40 \%($ mean $=24 \%)$ by $2100($ Fig. 4; Supplementary Fig. S14). This equals a Carbon loss of $20-52 \mathrm{~kg} \mathrm{C} \mathrm{m}^{-2}$ (mean $32 \mathrm{~kg} \mathrm{C} \mathrm{m}^{-2}$ ) over the next 90 years which is markedly higher than the $1-5 \mathrm{~kg} \mathrm{C}$ $\mathrm{m}^{-2}$ loss (1-4\%) without considering heat production.

Our results suggest a critical shift from a first phase of relatively slow permafrost thaw driven by climate changes and low heat production to a second phase of accelerated permafrost thaw when water is drained and increasing oxygen availability markedly triggers a higher heat production. The most critical model parameters for determining the tipping point of the accelerated permafrost thawing include initial ice/water content, soil hydraulic conditions, and the reactivity of the soil. As shown (Supporting Fig. S15), accelerated subsurface heat production is closely related to the time when all ground ice has melted and the total water content subsequently starts to decrease.

In the simulations, we have provided a conservative estimate of the importance of heat production using moderate climate scenarios, assuming that decomposition only takes place in non-saturated 
thawing layers (Supplementary Fig. S11) excluding anoxic decay processes which may produce additional heat in water-saturated layers ${ }^{3}$. We assumed that the present-day water balance and vegetation cover are representative for the future, which may not be the case. More precipitation may keep the soil water saturated and reduce the effect of heat production reported here. On the other hand, drier conditions may increase the heat production and further accelerate thawing. Oxygen depletion caused by the decomposition itself was not included in our model. This could be an important limiting factor, especially in soils where temperatures increase rapidly due to heat production. However, in some types of organic soils (palsas, pingos and kitchen middens), this may be counteracted by soil settling and erosion exposing deeper layers to atmospheric conditions.

We have shown that different types of organic soils from different parts of Greenland all have great heat production potential. We have estimated the impact of the internal heat production in thawing permafrost and conclude that climate change induced permafrost decomposition can be markedly enhanced in organic soils compared to other soil types due to internal heat production. The heat production is not only expected to accelerate the organic $\mathrm{C}$ decomposition and potentially the amounts of $\mathrm{C}$ emitted to the atmosphere but could be the tipping point that will lead to the loss of evidence of early human history in the Arctic, which so far has been extremely well-preserved in the top permafrost. 


\section{Methods}

\section{Study and sampling sites}

We used 21 samples which were collected from 16 contrasting organic permafrost soils located in 6 different areas in Greenland that were all within the continuous permafrost zone (Fig. 1). In the model, we focussed on two contrasting sites: a kitchen midden at Qajaa in West Greenland and a peatland at Zackenberg in North-east Greenland:

The Qajaa midden, situated $18 \mathrm{~km}$ south-east of Ilulissat in the western central part of Greenland, was selected as the main study site for investigating the coupling between climate, soil temperatures, decomposition and heat production. The midden has been known at least since 1871 and is considered the site with the best preserved organic remains from the Palaeo-Eskimo Saqqaq and Dorset cultures in all of Greenland ${ }^{11,25}$. It covers an area of approx. $2,900 \mathrm{~m}^{2}$, has a maximum thickness of $3 \mathrm{~m}$ and consists of peat as well as rocks from fireplaces, animal bones and wood ${ }^{11}$. Due to its great historical value, the midden has been monitored since 2009 in order to evaluate current and future preservation conditions $^{11,25-26}$. The climate in the area is arctic with a mean annual temperature of $-4.5 \pm 1.7^{\circ} \mathrm{C}$ (1974 to 2004) and a mean annual amount of precipitation of $266 \mathrm{~mm}(1961 \text { to } 1984)^{27}$.

The peatland is situated in the Zackenberg Valley near the Zackenberg Research Station in central North-east Greenland $\left(74^{\circ} 30^{\prime} \mathrm{N} ; 20^{\circ} 30^{\prime} \mathrm{W}\right)$. The climate is high arctic, with a mean annual air temperature of $-9.1{ }^{\circ} \mathrm{C}$ and a mean annual amount of precipitation of $220 \mathrm{~mm}$, with $90 \%$ falling as snow and sleet. Zackenberg is located in the continuous permafrost zone, and the permafrost thickness has been estimated to be around $400 \mathrm{~m}^{28}$. 


\section{Sampling and analyses}

Sampling was based on excavation of pits down to the frost table followed by drilling to obtain intact permafrost cores. Top permafrost cores were collected by motorized hand-drilling equipment consisting of a Stihl drilling engine, an expandable drill string and a $40 \mathrm{~cm}$ long core barrel with a drill head. Sample lengths from 3 to $30 \mathrm{~cm}$ were packed in plastic bags and kept frozen. The heat production was measured at $16{ }^{\circ} \mathrm{C}$ using a thermal activity monitor (type 2277 , Thermometric, Sweden, or C3analysentechnik, Germany) equipped with ampoule cylinders (4 ml twin, type 2277-201, and $20 \mathrm{ml}$ twin, type 2230). Oxygen consumption rates were measured by monitoring the decrease of headspace $\mathrm{O}_{2}$ concentrations over time using oxygen optodes (PreSens) in three replicates ${ }^{14}$. Three replicate subsamples (1-2 g) of humid soil were transferred to $12.1 \mathrm{ml}$ glass vials flushed with atmospheric air and the vials sealed carefully using a disc of transparent commercial oxygen barrier film $\left(\mathrm{Escal}^{\mathrm{TM}}\right)$, a silicone gasket and a screw cap with aperture.

\section{Modelling}

Atmospheric conditions were governed by time-variant meteorological inputs, and the model incorporated interface processes from snow and vegetation cover at the boundary between atmosphere and soil. The model regime consisted of a $20 \mathrm{~m}$ deep profile divided into 82 layers. The upper 55 layers (3 m) were considered to be completely organic except from the upper $20 \mathrm{~cm}$ organic-rich top soil layer. The soil below $3 \mathrm{~m}$ was considered similar to the entisol/cryosols normally found in these parts of Greenland ${ }^{29}$. The temperature was kept constant at the lower boundary of the model regime. The thermal conductivity $\left(\mathrm{k}_{\mathrm{h}}\right)$ was calculated as a function of soil solids and soil moisture based on empirical equations adjusted to accommodate observations on the volumetric water content based on 
previous investigations ${ }^{30}$. The unfrozen and frozen values of $\mathrm{k}_{\mathrm{h}}$ were adjusted to match measured values (Supplementary Figure S5). For the layers below $3 \mathrm{~m}$, values of $\mathrm{k}_{\mathrm{h}}$ were based on default values for mineral soils. To adjust the thermal conductivity individually for each soil layer, a scaling coefficient was applied ${ }^{17}$.

Total modelled soil respiration $\mathrm{R}$ was the sum of three pool-specific respiration rates, each of which were simulated (See Supplementary Methods equation (1)) as the pool-specific decay rate multiplied by the total initial $\mathrm{C}$ pool multiplied by a fractionation coefficient that describes the ratio of the $\mathrm{C}$ pool to the total C pool (See Supplementary Methods equation (2)). The heat production used in the model was the mean value of all measurements (excluding the high values from Disko that were considered as outliers).

Climate change scenarios used in the CoupModel to predict future ground temperatures were based on IPCC RCP $4.5^{18}$ with the increase in air temperature by 2100 relative to the 1986-2005 mean and an Arctic amplification by a factor of two ${ }^{19}$. The two scenarios are: 1) a low range with a summer warming of $1.1{ }^{\circ} \mathrm{C}$ and winter warming of $3.3{ }^{\circ} \mathrm{C}$ and 2) a high range: summer warming of $4.2^{\circ} \mathrm{C}$ and winter warming of $6.2^{\circ} \mathrm{C}$. 


\section{References}

1. Schuur E. A. G., et al. Vulnerability of permafrost carbon to climate change: Implications for the global carbon cycle. Bioscience, 58(8), 701-714 (2008).

2. Schaefer K., et al. The impact of the permafrost carbon feedback on global climate. Env Res Lett, 9, 085003 (2014).

3. Khvorostyanov D. V., et al. Vulnerability of permafrost carbon to global warming. Part I: model description and role of heat generated by organic matter decomposition. Tellus Series $B$ Chemical and Physical Meteorology, 60(2), 250-264 (2008).

4. Heimann M.\& Reichstein M. Terrestrial ecosystem carbon dynamics and climate feedbacks. Nature, 451(7176), 289-292 (2008).

5. Rasmussen M., et al. Ancient human genome sequence of an extinct Palaeo-Eskimo. Nature, 463(7282), 757-762 (2010).

6. Tarnocai C., et al. Soil organic carbon pools in the northern circumpolar permafrost region. Glob Biogeochem Cycle, 23, GB2023 (2009).

7. Hugelius G., et al. Estimated stocks of circumpolar permafrost carbon with quantified uncertainty ranges and identified data gaps. Biogeosciences, 11, 6573-6593 (2014).

8. Schadel C., et al. Circumpolar assessment of permafrost $\mathrm{C}$ quality and its vulnerability over time using long-term incubation data. Global Change Biology, 20(2), 641-652 (2014).

9. Paré M. \& Bedard-Haughn A. Surface Soil Organic Matter Qualities of Three Distinct Canadian Arctic Sites. Arctic, Antarctic, and Alpine Research, 45(1), 88-98 (2013).

10. Biasi C., et al. Temperature-dependent shift from labile to recalcitrant carbon sources of arctic heterotrophs. Rapid Commun Mass Spectrom, 19(11), 1401-1408 (2005).

11. Elberling B., et al. Paleo-Eskimo kitchen midden preservation in permafrost under future climate conditions at Qajaa, West Greenland. Journal of Archaeological Science, 38(6), 13311339 (2011). 
12. Elberling B., Schippers A. \& Sand W. Bacterial and chemical oxidation of pyritic mine tailings at low temperatures. J. Contam Hydrol, 41(3-4), 225-238 (2000).

13. Hollesen J., Elberling B.\& Jansson P. E. Future active layer dynamics and carbon dioxide production from thawing permafrost layers in Northeast Greenland. Global Change Biology, 17(2), 911-926 (2011).

14. Matthiesen H. A novel method to determine oxidation rates of heritage materials in vitro and in situ. Studies in Conservation, 52(4), 271-280 (2007).

15. Hamdi S., et al. Synthesis analysis of the temperature sensitivity of soil respiration from laboratory studies in relation to incubation methods and soil conditions. Soil Biol Biochem, 58, $115-126$ (2013).

16. Elberling B., et al. Long-term $\mathrm{CO}_{2}$ production following permafrost thaw. Nature Clim Change, 3(10), 890-894 (2013).

17. Jansson P. E. \& Karlberg L. Coupled heat and mass transfer model for soil-plant-atmosphere systems. Stockholm, Sweden: Royal Institute of Technology, Dept of civil and Environmental Engineering, Report No.: 3087 (2004).

18. Collins, M., et al. Long-term Climate Change: Projections, Commitments and Irreversibility. In: Climate Change 2013: The Physical Science Basis. Contribution of Working Group I to the Fifth Assessment Report of the Intergovernmental Panel on Climate Change [Stocker, T.F., D. Qin, G.-K. Plattner, M. Tignor, S.K. Allen, J. Boschung, A. Nauels, Y. Xia, V. Bex and P.M. Midgley (eds.)]. Cambridge University Press, Cambridge, United Kingdom and New York, NY, USA.

19. Rinke A. \& Dethloff K. Simulated circum - Arctic climate changes by the end of the 21st century. Global and Planetary Change, 62(1-2), 173-186 (2008).

20. Kirschbaum M. U. F. Soil respiration under prolonged soil warming: are rate reductions caused by acclimation or substrate loss? Global Change Biology, 10(11), 1870-1877 (2004).

21. Eliasson P. E., et al. The response of heterotrophic $\mathrm{CO}_{2}$ flux to soil warming. Global Change Biology, 11(1), 167-181 (2005). 
22. Knorr W., Prentice I. C., House J. I. \& Holland E. A. Long-term sensitivity of soil carbon turnover to warming. Nature, 433(7023), 298-301 (2005).

23. Knoblauch C., et al. Predicting long-term carbon mineralization and trace gas production from thawing permafrost of Northeast Siberia. Global Change Biology, 19, 1160-1172 (2013).

24. Elberling B. Seasonal trends of Soil $\mathrm{CO}_{2}$ dynamics in a soil subject to freezing. Journal of Hydrology, 276(1-4), 159-175 (2003).

25. Hollesen J., et al. The Future Preservation of a Permanently Frozen Kitchen Midden in Western Greenland. Conservation and mgmt of arch sites, 14, 159-168 (2012).

26. Matthiesen H., et al. Degradation of Archaeological Wood Under Freezing and Thawing Conditions - Effects of Permafrost and Climate Change. Archaeometry: 56(3), 479-495 (2014).

27. Carstensen L. S. \& Jørgensen B. V. Weather and Climate Data from Greenland 1958-2010 Dataset available for research and educational purposes. DMI Technical Report 11-10. Danish Meteorological Institute. Copenhagen. (2011).

28. Christiansen H. H., et al. Permafrost and periglacial geomorphology at Zackenberg. Advances in Ecological Research, 40, 151-174 (2008).

29. Elberling B. \& Jakobsen B. H. Soil solution pH measurements using in-line chambers with tension lysimeters. Canadian Journal of Soil Science, 80, 283-288 (2008).

30. Kersten M. S. Thermal properties of soils. Inst. of Technology, Eng. Exp. Station, Bull. No. 28, 26 pp., Minneapolis: Univ. Minnesota (1949). 


\section{Acknowledgements}

We gratefully acknowledge the financial support from the Danish National Research Foundation (CENPERM DNRF100), from the Augustinus foundation (Northern Worlds) and the Carlsberg Foundation. We acknowledge the Zackenberg Basic programme for providing meteorological data and extend our gratitude to Per Erik Jansson from the Royal Institute of Technology, Stockholm Sweden.

\section{Author contribution}

BE \& HMA initiated the collaboration project, BE, JHO \& HMA collected samples and performed fieldwork. JHO and ABM performed laboratory investigations, and JHO compiled and analysed the data and performed the modelling. JHO \& BE wrote the paper with input from all co-authors.

\section{Competing financial interests}

The authors declare no competing financial interests.

\section{Corresponding author}

For correspondence and requests for material please contact Bo Elberling, Center for Permafrost (CENPERM), Department of Geosciences and Natural Resource Management, University of Copenhagen, Denmark. E-mail: be@ign.ku.dk 


\section{Figure Legends}

Figure 1 | Study site locations. Study sites spread across the continuous permafrost zone in Greenland. Black symbols represent the 6 areas where 21 different samples of organic permafrost soils were collected for the analysis. The location of the Disko Bay region is shown as a black square.

Figure $2 \mid$ Heat production during incubation at $16{ }^{\circ} \mathrm{C}$. Observed heat production in 21 different organic rich permafrost samples (in situ water content) grouped according to soil type and sample area. The n-values represent different locations within a specific area - except for the Qajaa midden where $\mathrm{n}$ represents the number of different archaeological layers investigated. Error bars show +1 standard deviation. For comparison heat production from a mineral soil at Zackenberg ${ }^{13}$ is included.

Figure 3 | Simulated soil temperatures in the Disko Bay area (left) and the Zackenberg area (right). (A) Climate change scenario 1 (low), (B) Climate change scenario 2 (high), and (C) Climate change scenario 2 (high) with mean measured heat production. Model simulations based on the mean measured heat production \pm 1 standard deviation are shown in Supplementary Figs. S12-13.

Figure 4 | Simulated organic carbon loss in the Disko Bay Area. (A) Climate change scenario 2 (high) and (B) Climate change scenario 2 (high) with mean measured heat production. The results for the mean measured heat production \pm 1 standard deviation are shown in Supplementary Fig. S14. 